\title{
Molecular Characterization Reveals Genetic Uniformity in Experimental Chicken Resources
}

\author{
Ryo TADANO ${ }^{1)}$, Keiji KINOSHITA ${ }^{2)}$, Makoto MIZUTANI ${ }^{2)}$, Yuusuke ATSUMI ${ }^{2)}$, \\ Akira FUJIWARA $^{3)}$, Toshiki SAITOU ${ }^{3)}$, Takao NAMIKAWA ${ }^{2)}$, and Masaoki TSUDZUKI ${ }^{1)}$ \\ ${ }^{1)}$ Laboratory of Animal Breeding and Genetics, Graduate School of Biosphere Science, Hiroshima \\ University, Higashi-Hiroshima, Hiroshima 739-8528, Japan, ${ }^{2}$ Nagoya University Avian Bioscience \\ Research Center, Nagoya, Aichi 464-8601, Japan, and ${ }^{3}$ Laboratory Animal Research Station, \\ Nippon Institute for Biological Science, Hokuto, Yamanashi 408-0041, Japan
}

\begin{abstract}
The objective of the present study was to conduct the genetic characterization of nine experimental chicken lines based on multilocus microsatellite analysis. Commercial chicken lines were also analyzed in order to compare their levels of genetic uniformity with those of the experimental lines. In six experimental lines, more than $80 \%$ of genotyped loci showed fixed allele for all individuals in each line, whereas only $17.5 \%$ of genotyped loci were fixed in commercial lines, at the maximum. One of experimental lines (GSN/1) was categorized as a highly inbred line on the basis of all individuals having the same, single allele at every microsatellite locus. Genetic information obtained from the present study should be helpful for the utilization and management of experimental chicken resources.

Key words: experimental chicken resource, genetic uniformity, microsatellite polymorphism
\end{abstract}

Mice and rats are the most important and widely used laboratory animals in various fields of research. The chicken is also a valuable vertebrate model because of some advantages such as a high rate of embryo production, defined genotypes and phenotypes, ZW female sex determination, and a compact genome [2]. Additionally, the chicken is the first avian species to have had its genome sequenced [5]. To date, many specialized experimental chicken lines have been established and they have contributed to significant advances in biological and agricultural sciences [3]. For example, inbred and congenic lines have been used for the identification of genes controlling resistance to chicken disease [1].

Despite their high importance, the number of experimental poultry resources including chickens continues to be decrease [2]. For example, a survey documented that at least 10 experimental poultry resources disappeared from North America during the first 9 months of 2005 and that 30 resources disappeared during 2004 [2]. In addition, the establishment of specialized chicken lines, in particular inbred lines, is laborious, because it takes a large amount of time to achieve genetic uniformity. Domesticated bird species generally undergo inbreeding depression caused by continuous mating among related individuals (e.g., full-sib mating). Hence, existing experimental resources are highly valuable.

In Japan, several experimental chicken resources including inbred lines have been maintained at Nagoya University Avian Bioscience Research Center (NUABRC) (http://www.agr.nagoya-u.ac.jp/ abrc/). In the

(Received 1 December 2009 / Accepted 28 February 2010)

Address corresponding: M. Tsudzuki, Laboratory of Animal Breeding and Genetics, Graduate School of Biosphere Science, Hiroshima University, Higashi-Hiroshima, Hiroshima 739-8528, Japan 
Table 1. Summary information of the nine experimental chicken lines investigated

\begin{tabular}{|c|c|c|c|c|}
\hline Line & Breed & Breeding history & $\begin{array}{l}\text { B blood } \\
\text { group }^{\text {a) }}\end{array}$ & $\begin{array}{l}\text { Inbreeding } \\
\text { coefficient }^{\text {b) }}\end{array}$ \\
\hline WL-G & $\begin{array}{l}\text { White } \\
\text { Leghorn }\end{array}$ & $\begin{array}{l}\text { This line was established in } 1969 \text { at Nagoya University and has been } \\
\text { maintained as a closed colony by random mating. }\end{array}$ & B 12 & ND \\
\hline BL-E & $\begin{array}{l}\text { Brown } \\
\text { Leghorn }\end{array}$ & $\begin{array}{l}\text { This line was imported from Edinburgh Poultry Research Center in } \\
1960 \text { and has been maintained as a closed colony by random mating } \\
\text { at Nagoya University. }\end{array}$ & B12 & ND \\
\hline RIR-Y8/NU & $\begin{array}{l}\text { Rhode Island } \\
\text { Red }\end{array}$ & $\begin{array}{l}\text { This line was introduced to Nagoya University from National Livestock } \\
\text { Breeding Center, Okazaki in } 1980 \text {. Since then, random mating has } \\
\text { been conducted in a closed colony. }\end{array}$ & B12 & ND \\
\hline AL-NU & $\begin{array}{l}\text { Black } \\
\text { Australorp }\end{array}$ & $\begin{array}{l}\text { This line was introduced to Nagoya University from National Institute } \\
\text { of Genetics in } 1981 \text { and has been maintained as a closed colony by } \\
\text { random mating. }\end{array}$ & ND & ND \\
\hline BM-C & $\begin{array}{l}\text { Black } \\
\text { Minorca }\end{array}$ & $\begin{array}{l}\text { This line was introduced to Nagoya University from University of } \\
\text { Connecticut in 1959. In 1970, pedigree mating was started based } \\
\text { on one male and two females. }\end{array}$ & B15 & $92 \%$ \\
\hline YL & Fayoumi & $\begin{array}{l}\text { This line was initiated in } 1972 \text { at Nippon Institute for Biological Science } \\
\text { and has been maintained as a small closed colony by pedigree mating. }\end{array}$ & B21 & $85 \%^{\mathrm{c})}$ \\
\hline PNP/DO & Fayoumi & $\begin{array}{l}\text { This line was initiated in } 1971 \text { at Nippon Institute for Biological Science } \\
\text { and has been maintained as a small closed colony by pedigree mating. }\end{array}$ & B1 & $95 \%$ \\
\hline GSP & Fayoumi & $\begin{array}{l}\text { This line was initiated in } 1971 \text { at Nippon Institute for Biological Science } \\
\text { and has been maintained as a small closed colony by pedigree mating. }\end{array}$ & B21 & $96 \%$ \\
\hline GSN/1 & Fayoumi & $\begin{array}{l}\text { This line was initiated in } 1971 \text { at Nippon Institute for Biological Science } \\
\text { and has been maintained as a small closed colony by pedigree mating. }\end{array}$ & B21 & $97 \%$ \\
\hline
\end{tabular}

${ }^{a}[6,7,12] . \mathrm{ND}=$ not determined. ${ }^{\mathrm{b})}$ Based on band sharing $(\mathrm{BS})$ value detected by AFLP analysis [6,7]. ND= not determined. ${ }^{\mathrm{c}} \mathrm{Based}$ on restriction fragment length polymorphism analysis (data by M. Mizutani). More information is available from the NUABRC website (http://www.agr.nagoya-u.ac.jp/\%7Eabrc/bioresourse.html) and other articles [6,7].

establishment of these lines, genetic uniformity of individuals in each line was promoted by fixing red blood cell types detected by isoimmune sera, various plant lectins, and a few virus agglutinins. For future utilization and sustainable management of these resources, individual resources will need precise characterization at the DNA level.

In the present study, we assessed the degree of inbreeding in nine experimental chicken resources, which include inbred lines established by long-term pedigree mating, based on microsatellite analysis. The level of microsatellite polymorphisms in experimental lines was compared with that of commercial chicken lines (commonly used layers and broilers).

In total, nine experimental chicken lines, WL-G, BLE, RIR-Y8/NU, AL-NU, BM-C, YL, PNP/DO, GSP, and GSN/1, which are now kept at the Nagoya University Avian Bioscience Research Center (NUABRC) (http:// www.agr.nagoya-u.ac.jp/ abrc/), were investigated. The breeding history, fixed allele in the B blood group, and inbreeding coefficient of these lines are summarized in Table 1. More information and the genetic characteristics of these lines can be obtained from the NUABRC website (http://www.agr.nagoya-u.ac.jp/\% 7Eabrc/bioresourse.html) and other articles [6,7]. Five lines (BM-C, YL, PNP/DO, GSP, and GSN/1) have been established by pedigree mating for around 40 years $[6,7]$. The four lines excluding YL have a more than $90 \%$ inbreeding coefficient based on the band sharing (BS) value detected by amplified fragment length polymorphism (AFLP) analysis [6,7]. The detailed pedigrees of these five lines are described elsewhere $[11,12]$. The remaining four lines (WL-G, BL-E, RIR-Y8/NU, and AL-NU) have been maintained as a random-bred closed colony over 30-50 years (http://www.agr.nagoya-u.ac.jp/ abrc/). To evaluate the genetic uniformity of the experimental 
Table 2. Allelic distribution of 40 microsatellite loci and mean heterozygosity of the experimental and commercial chicken lines

\begin{tabular}{|c|c|c|c|c|c|c|c|c|c|c|c|c|c|c|c|}
\hline \multirow[b]{3}{*}{ Loci } & \multirow[b]{3}{*}{ Chr. (cM) ${ }^{\mathrm{b}}$} & \multicolumn{14}{|c|}{ Number of alleles detected } \\
\hline & & \multicolumn{9}{|c|}{ Experimental chicken lines } & \multicolumn{5}{|c|}{ Commercial chicken lines ${ }^{\mathrm{a})}$} \\
\hline & & $\begin{array}{l}\text { WL-G } \\
(n=20)\end{array}$ & $\begin{array}{l}\text { BL-E R } \\
(\mathrm{n}=16)\end{array}$ & $\begin{array}{c}\text { RIR-Y8/NU } \\
(\mathrm{n}=24)\end{array}$ & $\begin{array}{l}\text { AL-NU } \\
(\mathrm{n}=16)\end{array}$ & $\begin{array}{l}\text { BM-C } \\
(n=23)\end{array}$ & $\begin{array}{c}\mathrm{YL} \\
(\mathrm{n}=23)\end{array}$ & $\begin{array}{c}\mathrm{PNP} / \mathrm{DO} \\
(\mathrm{n}=23)\end{array}$ & $\begin{array}{c}\text { GSP } \\
(\mathrm{n}=24)\end{array}$ & $\begin{array}{l}\mathrm{GSN} / 1 \\
(\mathrm{n}=28)\end{array}$ & $\begin{array}{l}\text { WEL-1 } \\
(\mathrm{n}=48)\end{array}$ & $\begin{array}{l}\text { WEL-2 } \\
(\mathrm{n}=48)\end{array}$ & $\begin{array}{c}\text { BEL } \\
(\mathrm{n}=41)\end{array}$ & $\begin{array}{c}\text { BR-1 } \\
(\mathrm{n}=47)\end{array}$ & $\begin{array}{c}\text { BR-2 } \\
(\mathrm{n}=48)\end{array}$ \\
\hline MCW0248 & $1(19)$ & 1 & 1 & 2 & 1 & 1 & 1 & 1 & 1 & 1 & 1 & 2 & 3 & 3 & 3 \\
\hline MCW0112 & $1(205)$ & 3 & 1 & 1 & 1 & 1 & 1 & 1 & 1 & 1 & 3 & 4 & 3 & 4 & 4 \\
\hline ADL0268 & $1(288)$ & 3 & 1 & 3 & 1 & 1 & 1 & 1 & 1 & 1 & 3 & 4 & 4 & 5 & 5 \\
\hline MCW0145 & $1(455)$ & 3 & 1 & 2 & 2 & 1 & 1 & 1 & 1 & 1 & 3 & 5 & 4 & 8 & 7 \\
\hline ADLO190 & $2(62)$ & 2 & 2 & 2 & 1 & 1 & 1 & 1 & 2 & 1 & 2 & 2 & 4 & 4 & 5 \\
\hline$A D L 0257$ & $2(153)$ & 1 & 2 & 3 & 2 & 1 & 1 & 1 & 1 & 1 & 1 & 3 & 2 & 5 & 6 \\
\hline LEI0096 & $2(233)$ & 3 & 1 & 1 & 2 & 1 & 2 & 1 & 1 & 1 & 3 & 5 & 4 & 3 & 6 \\
\hline MCW0034 & $2(233)$ & 2 & 1 & 2 & 2 & 1 & 2 & 1 & 1 & 1 & 3 & 4 & 6 & 5 & 6 \\
\hline LEIO228 & $2(390)$ & 1 & Missing ${ }^{\mathrm{c}}$ & 3 & 2 & 1 & 1 & 1 & 1 & 1 & 3 & 2 & 7 & 8 & 9 \\
\hline ADL0146 & $2(403)$ & 1 & 1 & 2 & 1 & 1 & 1 & 1 & 1 & 1 & 2 & 2 & 4 & 4 & 4 \\
\hline MCW0222 & $3(85)$ & 1 & 1 & 2 & 1 & 1 & 1 & 1 & 1 & 1 & 2 & 2 & 3 & 3 & 3 \\
\hline MCW0252 & $3(201)$ & 1 & 1 & 2 & 2 & 1 & 1 & 1 & 1 & 1 & 3 & 3 & 4 & 7 & 6 \\
\hline MCW0037 & $3(317)$ & 1 & 1 & 1 & 1 & 1 & 1 & 1 & 1 & 1 & 3 & 1 & 3 & 3 & 5 \\
\hline MCW0295 & $4(75)$ & 2 & 1 & 3 & 2 & 2 & 1 & 1 & 1 & 1 & 4 & 5 & 3 & 4 & 5 \\
\hline MCW0167 & $4(114)$ & 1 & 1 & 2 & 1 & 1 & 1 & 1 & 1 & 1 & 3 & 2 & 2 & 4 & 3 \\
\hline MCW0240 & $4(201)$ & 1 & 2 & 1 & 1 & 1 & 1 & 2 & 1 & 1 & 2 & 2 & 6 & 7 & 8 \\
\hline MCW0193 & $5(50)$ & 2 & 1 & 3 & 1 & 1 & 1 & 1 & 1 & 1 & 5 & 6 & 4 & 5 & 6 \\
\hline MCW0078 & $5(93)$ & 1 & 2 & 2 & 1 & 1 & 1 & 1 & 1 & 1 & 2 & 4 & 2 & 2 & 3 \\
\hline MCW0081 & $5(151)$ & 1 & 1 & 2 & 1 & 1 & 1 & 1 & 1 & 1 & 2 & 4 & 1 & 2 & 4 \\
\hline LEIO196 & $6(110)$ & 2 & 1 & 2 & 1 & 1 & 1 & 1 & 1 & 1 & 4 & 4 & 3 & 9 & 10 \\
\hline MCW0183 & $7(86)$ & 2 & 1 & 2 & 1 & 1 & 1 & 1 & 1 & 1 & 3 & 3 & 4 & 4 & 6 \\
\hline ADL0169 & $7(165)$ & 1 & 1 & 1 & 1 & 1 & 1 & 1 & 1 & 1 & 2 & 2 & 6 & 4 & 4 \\
\hline ADL0258 & $8(23)$ & 1 & 1 & 1 & 1 & 1 & 1 & 1 & 1 & 1 & 4 & 3 & 4 & 4 & 6 \\
\hline$A D L 0278$ & $8(94)$ & 2 & 1 & 1 & 1 & 1 & 1 & 1 & 1 & 1 & 4 & 3 & 5 & 4 & 2 \\
\hline ADL0191 & $9(44)$ & 2 & 1 & 2 & 1 & 1 & 1 & 1 & 1 & 1 & 4 & 4 & 2 & 5 & 4 \\
\hline MCW0134 & $9(132)$ & 2 & 1 & 2 & 1 & 1 & 1 & 1 & 1 & 1 & 2 & 4 & 4 & 8 & 9 \\
\hline MCW0067 & $10(59)$ & 2 & 1 & 1 & 2 & 2 & 2 & 1 & 1 & 1 & 4 & 3 & 2 & 3 & 3 \\
\hline ADL0106 & $10(88)$ & 1 & 1 & 2 & 1 & 2 & 1 & 1 & 1 & 1 & 1 & 2 & 3 & 4 & 4 \\
\hline$A D L 0210$ & $11(54)$ & 1 & 2 & 1 & 1 & 1 & 1 & 2 & 1 & 1 & 3 & 3 & 3 & 4 & 5 \\
\hline LEI0099 & $12(63)$ & 2 & 1 & 2 & 2 & 1 & 1 & 1 & 1 & 1 & 4 & 4 & 3 & 5 & 4 \\
\hline$A D L 0147$ & $13(32)$ & 1 & 2 & 2 & 2 & 1 & 1 & 2 & 1 & 1 & 1 & 2 & 4 & 4 & 4 \\
\hline$M C W 0123$ & $14(45)$ & 1 & 1 & 1 & 1 & 1 & 1 & 1 & 2 & 1 & 2 & 1 & 4 & 4 & 3 \\
\hline MCW0330 & $17(41)$ & 2 & 1 & 2 & 2 & 2 & 1 & 1 & 1 & 1 & 1 & 2 & 4 & 4 & 4 \\
\hline$M C W 0217$ & $18(24)$ & 1 & 1 & 2 & 1 & 1 & 1 & 1 & 2 & 1 & 1 & 3 & 4 & 6 & 7 \\
\hline MCW0287 & $19(40)$ & 1 & 1 & 2 & 2 & 1 & 1 & 1 & 1 & 1 & 3 & 1 & 2 & 7 & 6 \\
\hline MCW0165 & $23(1)$ & 1 & 1 & 2 & 1 & 1 & 1 & 1 & 1 & 1 & 3 & 3 & 2 & 3 & 3 \\
\hline MCW0301 & $24(48)$ & 2 & 1 & 3 & 1 & 1 & 1 & 1 & 1 & 1 & 3 & 4 & 3 & 7 & 7 \\
\hline MCW0069 & $26(47)$ & 2 & 1 & 2 & 2 & 1 & 2 & 1 & 1 & 1 & 2 & 3 & 3 & 4 & 3 \\
\hline MCW0233 & 27 (19) & 1 & 1 & 2 & 1 & 1 & 1 & 1 & 1 & 1 & 1 & 2 & 4 & 4 & 3 \\
\hline$A D L 0284$ & $28(25)$ & 1 & 1 & 2 & 1 & 1 & 2 & 1 & 1 & 1 & 5 & 6 & 8 & 10 & 12 \\
\hline $\mathrm{MNA}^{\mathrm{d})}$ & & 1.55 & 1.15 & 1.90 & 1.33 & 1.10 & 1.13 & 1.08 & 1.08 & 1.00 & 2.68 & 3.10 & 3.65 & 4.83 & 5.18 \\
\hline Fixed loci & & $22 / 40$ & $33 / 39$ & $10 / 40$ & $27 / 40$ & $36 / 40$ & $35 / 40$ & $37 / 40$ & $37 / 40$ & $40 / 40$ & $7 / 40$ & $3 / 40$ & $1 / 40$ & $0 / 40$ & $0 / 40$ \\
\hline$(\%)$ & & $55.0 \%$ & $84.6 \%$ & $25.0 \%$ & $67.5 \%$ & $90.0 \%$ & $87.5 \%$ & $92.5 \%$ & $92.5 \%$ & $100 \%$ & $17.5 \%$ & $7.5 \%$ & $2.5 \%$ & $0 \%$ & $0 \%$ \\
\hline \multicolumn{2}{|c|}{ Heterozygosity) } & 0.193 & 0.058 & 0.348 & 0.133 & 0.030 & 0.035 & 0.023 & 0.032 & 0.000 & 0.517 & 0.640 & 0.676 & 0.684 & 0.708 \\
\hline
\end{tabular}

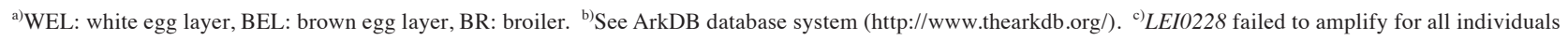
of BL-E line ( $\mathrm{n}=16) .{ }^{\mathrm{d})} \mathrm{Mean}$ number of alleles per locus (MNA = total number of alleles detected/total number of loci genotyped). ${ }^{\mathrm{e}}$ Mean observed heterozygosity within each line.

lines, commercial chicken lines were also analyzed for comparison. These were two white egg layers (WEL-1 and WEL-2), one brown egg layer (BEL), and two broil- ers (BR-1 and BR-2). These five lines, selected for quantitative traits, are commonly used for egg and meat production by the Japanese poultry industry. Genomic 
DNA of individual birds was extracted from whole blood by the standard phenol-chloroform method [8]. In consideration of genome coverage and degree of polymorphism, we selected the same 40 microsatellite markers as our previous study [9]. We used 16-28 birds per experimental line and 41-48 birds per commercial line for genotyping. The procedures of PCR amplification and genotyping were described in a previous article [10]. In order to assess the genetic uniformity of each line, the mean number of alleles per locus (MNA), the number of fixed loci, and the mean observed heterozygosity [4] were estimated using a Microsatellite Toolkit (http:// animalgenomics.ucd.ie/sdepark/ms-toolkit/).

Table 2 shows the allelic distribution of 40 microsatellite loci and within-line heterozygosity of the experimental and commercial lines. Except for three experimental lines (WL-G, RIR-Y8/NU, and AL-NU), more than $80 \%$ of genotyped microsatellite loci were fixed [ranging from $84.6 \%$ (BL-E) to $100 \%$ (GSN/1)] in the experimental lines. In contrast, the proportion of fixed loci in the five commercial lines was $17.5 \%$ at the maximum. Except for RIR-Y8/NU, heterozygosities estimated in the experimental lines were considerably low [ranging from $0.000(\mathrm{GSN} / 1)$ to 0.193 (WL-G)], in marked contrast to those of commercial lines [ranging from 0.517 (WEL-1) to 0.708 (BR-2)].

High levels of degree of inbreeding (low MNA, large number of fixed loci, and low heterozygosity) were observed in the lines established/maintained by long-term pedigree mating (BM-C, YL, PNP/DO, GSP, and GSN/1). In the microsatellite analysis by Zhou and Lamont [13], heterozygosity of the world's first long-term successful inbred chicken lines (lines 8-42, 19-45, and 19-46 initiated in 1925) were $0.023,0.000$, and 0.000 , respectively. In the present study, similar heterozygosity values were obtained (BM-C $=0.030, \mathrm{YL}=0.035, \mathrm{PNP} /$ $\mathrm{DO}=0.023, \mathrm{GSP}=0.032$, and GSN $/ 1=0.000$ ). This indicates that these five lines have high levels of genetic uniformity and that they are valuable chicken resources for biological research. In particular, GSN/1 is classified as a highly inbred line because every locus was fixed in all individuals.

On the other hand, lines established through random mating (WL-G, BL-E, RIR-Y8/NU, and AL-NU) showed low or intermediate degrees of inbreeding. In particular, RIR-Y8/NU showed the lowest degrees of inbreeding; that is, $75 \%$ of genotyped loci were polymorphic together with higher heterozygosity (0.348). RIR-Y8/NU might be classified as a low-order commercial line rather than an experimental line. To promote higher genetic uniformity, this line will need further inbreeding and selection.

The results obtained in the present study will be useful for the management of the experimental lines mentioned above. In concrete terms, designed mating based on microsatellite information of individual birds will be useful for promoting the genetic uniformity of these experimental lines.

\section{Acknowledgment}

The authors would like to thank Dr. L.M. Liao for proofreading the manuscript.

\section{References}

1. Bacon, L.D., Hunt, H.D., and Cheng, H.H. 2000. Poult. Sci. 79: 1082-1093.

2. Delany, M.E. 2006. Poult. Sci. 85: 223-226.

3. Fulton, J.E. and Delany, M.E. 2003. Science 300: 16671668 .

4. Hedrik, P.W. 1983. Genetics of Populations, Science Books International, Boston.

5. International Chicken Genome Sequencing Consortium. 2004. Nature 432: 695-716.

6. Mizutani, M. 2000. J. Anim. Genet. 28: 45-58 (in Japanese).

7. Mizutani, M. 2002. Exp. Anim. 51: 417-429.

8. Sambrook, J. and Russell D.W. 2001. Molecular Cloning: A Laboratory Manual, 3rd ed., Cold Spring Harbor Lab. Press, New York.

9. Tadano, R., Nishibori, M., Nagasaka, N., and Tsudzuki, M. 2007. Poult. Sci. 86: 2301-2308.

10. Tadano, R., Sekino, M., Nishibori, M., and Tsudzuki, M. 2007. Poult. Sci. 86: 460-469.

11. Valdes, M.B. Jr., Mizutani, M., Fujiwara, A., Yazawa, H., Yamagata, T., Shimada, K., and Namikawa, T. 2007. Exp. Anim. 56: 329-338.

12. Valdes, M.B. Jr., Kinoshita, K., Mizutani, M., Fujiwara, A., Yazawa, H., Yamagata, T., Shimada, K., and Namikawa, T. 2009. Exp. Anim. 58: 169-174.

13. Zhou, H. and Lamont, S.J. 1999. Anim. Genet. 30: 256264. 